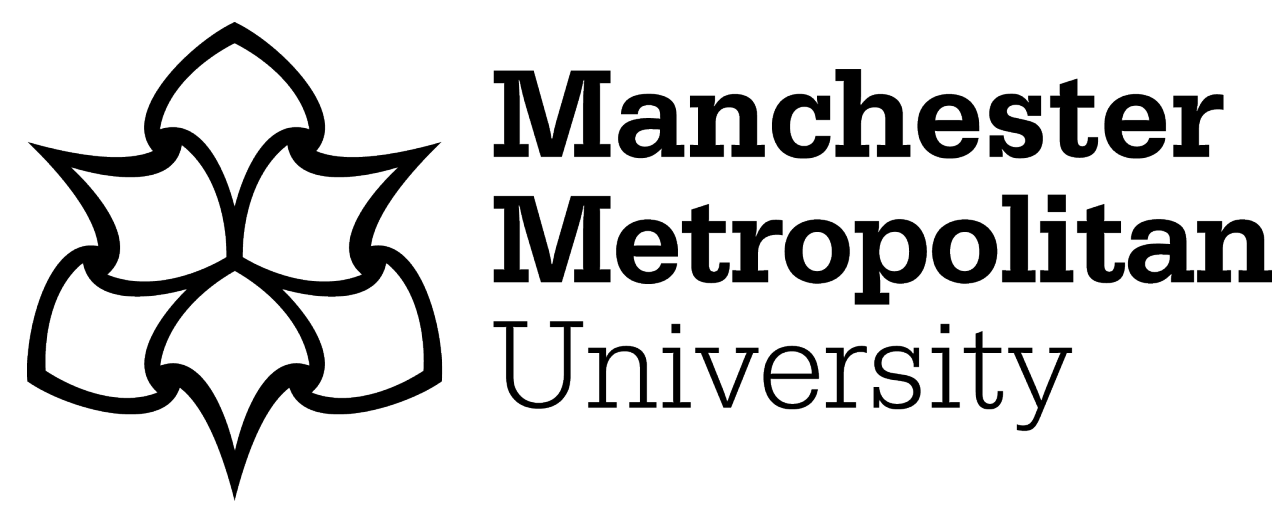

Davies, Julie ORCID logoORCID: https://orcid.org/0000-0002-6875-3100, Yarrow, Emily and Syed, Jawad (2020) The curious underrepresentation of women impact case leaders: can we disengender inequality regimes? Gender, Work \& Organization, 27 (2). pp. 129-148. ISSN 0968-6673

Downloaded from: https://e-space.mmu.ac.uk/623818/

Version: Accepted Version

Publisher: Wiley

DOI: https://doi.org/10.1111/gwao.12409

Please cite the published version 


\title{
The curious under-representation of women impact case leaders: Can we disengender inequality regimes?
}

\author{
Julie Davies ${ }^{1}$ \\ Emily Yarrow ${ }^{2}$ \\ Jawad Syed ${ }^{3}$ \\ ${ }^{1}$ Manchester Metropolitan University, UK \\ ${ }^{2}$ Portsmouth Business School, UK \\ ${ }^{3}$ Lahore University of Management Sciences, Lahore, Pakistan \\ Correspondence
}

Dr Julie Davies, Manchester Metropolitan University Email: jadavies777@gmail.com

\begin{abstract}
Universities are increasingly expected to demonstrate the wider societal impacts of academic research. Yet women management scholars were disproportionately under-represented in leading impact cases in the UK's REF (Research Excellence Framework) 2014. An analysis of 395 REF impact cases for business and management studies with an identifiable lead author revealed that only $25 \%$ were led by women, of which $54 \%$ were sole authored. Based on 12 indepth interviews with women impact case writers, we use Acker's inequality regimes framework to understand invisible and socially constructed gendering of the UK's policy that is designed to evaluate research impact. In a knowledge intensive workplace dominated by men, the shape and degree of gendered bases of inequality, systemic practices, processes, and controls result in suboptimal talent management and gendered knowledge. We call for university leaders to be proactive in addressing barriers that fail to support or recognise women's leadership of research impact.
\end{abstract}

KEYWORDS academics, gender, inequality regime, REF, research impact, women 


\section{1 | INTRODUCTION}

This article responds to Broadbridge and Simpson's (2011, p. 470) call 'to monitor and publicize...new forms of gendered power'. We explore women management scholars' leadership of impact case studies. Universities must increasingly demonstrate the wider societal reach and significance of the impact of academic research (e.g. Haley et al., 2017). This agenda has changed the behaviours of faculty members and business school leaders (Lejeune et al., 2015). Policies are driven by political ideologies about accountability (Neyland, 2007) in national research assessments which determine university funding (Aguinis et al., 2012). Willmott (1995, p. 994) suggested strong relationships in universities 'between capitalist values and priorities, mediated by political ideologies and programs, and the organisation and academic labour'. Yet we know little about the gendering of new policies in higher education.

Against this backdrop, universities provide interesting examples of precarious work places and of gender bias (Steinpórsdóttir et al., 2019; Yarrow, 2016). In the academy, men gain career advantage from peer networks (Crane, 1972; de Solla Price \& Beaver, 1966) of powerful, prestigious and influential 'in-groups' of other men who control research funding and new scientific ideas. Men in the academy benefit from the 'Matthew effect', i.e. 'overrecognition of those at the top of the scientific profession' (Merton 1973, p. 326). Meanwhile, women faculty members must overcome the 'Matilda effect' (Rossiter, 1993, p. 337), i.e. systematic neglect and under-recognition of them and their work. Gendered 'structural, cultural and procedural' arrangements (Benschop \& Brouns, 2003, p. 206), therefore, represent systemic processes which sustain gender disadvantage (Bird, 2011) by entrenching discriminatory attitudes and behaviours towards women in the academy.

Arguably, national research evaluations drive competition and the individualisation of academic work (see Abramo 2011; Brooks et al., 2014; Yarrow, 2016). Such contingencies create working conditions which favour the 'unencumbered worker' (Berns, 2002, p. 5). This 
stereotype is typically a man "who is totally dedicated to the work and who has no responsibilities for children and family demands other than earning a living' (Acker, 2009, p. 206).

In response to these challenges, our study is the first to explore why and how women management scholars were disproportionately under-represented in leading REF (Research Excellence Framework) 2014 impact cases for business and management studies. We draw on Acker's (2009, p. 201) 'idea of "Inequality Regimes” [which] is an analytic approach to understanding the on-going creation of inequalities in work organizations. It can be used to identify inequality-producing practices and their locations in particular organizing processes.' In this paper, we focus on persistent systemic bases for gender inequality, i.e. 'loosely interrelated practices, processes, actions, and meanings that result in and maintain ... gender ... inequalities' (Acker, 2009, p. 201). We examine men's dominance and cumulative advantage in the academy specifically in relation to empirical data based on the UK's research impact case agenda which was introduced in 2014. Acker's $(2006,2009)$ inequality regime metaphor is a useful framework to investigate why women scholars were under-represented in leading REF 2014 impact case studies.

Drawing on a thematic analysis of REF 2014 business and management impact cases and in-depth interviews with 12 women impact case writers, our findings show that women management scholars led only $25 \%$ of REF 2014 impact cases where a lead author was identified. It is interesting that $54 \%$ of these were sole women authors. As women in the UK represented $45 \%$ of all academics in 2013/14 (HESA, 2015), it is clear that they were under-represented in leadership positions in the first evaluation of research impact cases in the UK (Kellard \& Śliwa, 2016).

Although research impact might be expected to play to women scholars' strengths because of skills required in collaborative communications and socially responsible behaviours (Benschop \& Brouns, 2003), it appears that women are experiencing path- and status- 
dependent cumulative disadvantage (Cole \& Singer, 1991). This explains growing inequality that is difficult to overcome (DiPrete \& Eirich, 2006). Our study offers insights into masculine discursive practices in universities (Knights \& Richards, 2003). It also contributes to critical conversations in Gender, Work and Organization about the 'gendered substructure [that] underlies organizing and helps to explain the persistence of male dominance and female disadvantage, in spite of years of attempts to implement gender equity policies' (Acker, 1998, p. 197). We strongly resist assumptions about 'women themselves being the cause of gender inequalities' (Powell et al., 2018, p. 139).

This paper is structured as follows. First, we review inequality regimes in the academy using the lens of gender and discuss UK REF 2014 impact cases particularly for business and management studies. We then discuss our study's epistemology, methodology, and findings. Finally, we highlight our contributions to Acker's $(2006,2009)$ framework and make recommendations for practice, academic activism, and further research to enhance the representation and visibility of women management scholars in the impact agenda which is growing world-wide.

\section{2 | GENDER INEQUALITY REGIMES AND THE ACADEMY}

Our central research question is: why were women management scholars under-represented in leading REF 2014 impact cases? We are also interested in the composition of impact case teams led by women. In investigating these questions, we review literature on gender disparities in the academy by mobilizing three key characteristics of Acker's (2006, pp. 444-455) inequality regimes framework: (i) the bases of inequality; (ii) the shape and degree of inequality; and (iii) organizing processes that produce systemic inequality. From our iterative data analysis, three (of six) central facets from Acker's (2006) framework were prominent. These are explained in the next section. 


\section{1 | Gender as an enduring basis for workplace inequality}

The first facet of Acker's $(2006,2009)$ inequality regime framework we consider is the problem of arrangements that create persistent workplace inequality, i.e. 'barriers that obstruct women's opportunities for advancement at all levels of organizational hierarchy' (Acker, 2008, p. 199). Acker (2006, p. 443) defines workplace inequality regimes as 'systematic disparities between participants in power and control over goals, resources, and outcomes; workplace decisions such as how to organize work; opportunities for promotion and interesting work; security in employment and benefits; pay and other monetary rewards; respect; and pleasures in work and work relations'. Further, she highlights gendered inequality at the individual level based 'on the assumption that the ordinary worker is a man, an abstract person who has few obligations outside work that could distract him from the centrality of work' (Acker, 1998, p. 197).

Scholars have found evidence that gendered reasons for inequality in universities are often accounted for by '[m]asculine discursive norms and practices [which] have the effect of legitimizing the conquest of knowledge, the competition for scarce material and symbolic resources and the control of anything that might constitute an obstacle to such projects' (Knights \& Richards, 2003, p. 231). Often these discriminatory norms in business schools are presented as meritocratic (Śliwa \& Johansson, 2014) which helps us to understand why they endure.

Men appear to set the norms for gender bias in the academy. Men dominate the upper echelons on editorial boards (Metz \& Harzing, 2012), panels, and committees as decisionmakers for journal rankings, which determine performance measures in the sector. Adler and Harzing (2009) argue that academic and journal ranking systems mutually reinforce societal and organizational contexts to exclude outsiders, powerfully influencing what work is valued most in [gendered] terms in journal ranking lists. Yarrow (2016) notes there are only two threerated gender-focused journals (Gender and Society; Gender, Work \& Organization) of the four listed in the widely adopted 2018 Academic Journal Guide. This guide influences publishing, 
appointments, and promotions decisions, which Mingers and Willmott (2013, p. 1051) argue is resulting in a narrow 'research monoculture'.

\subsection{The shape and degree of inequality}

The second facet in Acker's $(2006,2009)$ framework is the shape and degree of gendered workplace inequality. These are manifested in the recognition, advancement, and gradient of organizational hierarchies for men and women. Acker (2006, p. 445) argues that 'especially at the top ... positions are almost always occupied by white men' who fit a culture of long uninterrupted working hours. Atewologun and Sealy (2014) found that seniority indicates an individual's gendered privilege. Indeed, men represented $76 \%$ of all UK business school professors in 2017/18 (HESA, 2019) which perpetuates women's disadvantage (Bird, 2011) at senior levels.

In the literature, the degree of inequality for women academics is typically associated with their lack of time, childcare responsibilities, gendered work life commitments (Aiston \& Jung, 2015) and greater willingness to engage in citizenship behaviours such as 'academic housework' (Heijstra et al., 2017) which decrease women's research productivity. Padavic et al. $(2019$, p. 1) found that in general 'the necessity of long work hours and the inescapability of women's stalled advancement' exacerbate workplace gender inequality. Women feel discriminated against for taking maternity leave (Maxwell et al., 2019) and typically their higher caring responsibilities than men at home and in work constrain travel for research collaborations (Eisend \& Schuchert-Güler, 2015; Tower \& Latimer, 2016), even in Norway (Kyvik, 1991). Women faculty members simply run out of time (Probert, 2005). Their lower status (Bentley, 2011), as there are disproportionately fewer women professors (Fletcher, 2007), means women are allocated less research time.

Gender inequality is compounded by gender pay disparity (Pells, 2019), powerful informal networks of men that privilege certain groups in appointment processes (Harris et al., 2013; 
Yarrow, 2016) and men being credited for work completed by women assistants (Acker, 2006). It might be assumed that the 'boundary work' (Gieryn, 1983) entailed in creating and evidencing research impact negatively affects encumbered women academics because of the time (sometimes outside office hours) needed to network across boundaries between the academy and other domains to generate social, economic, political, technological and environmental benefits. Disadvantage is often hidden and cumulative throughout an academic woman's career (Marini \& Meschitti, 2018). It is frequently characterised by the notion of the 'squeezed middle' (Yarrow, 2016) which refers to mid-career or mid-life women who are caring for both their (most often) teenage children and their own and/or a partner's elderly parents.

\section{3 | Organizing processes for impact: Systemic, invisible, and legitimised inequalities}

The third facet of Acker's $(2006,2009)$ framework we apply in this study are systemic organizing processes that (re)produce and legitimate visible and invisible gendered workplace inequalities. Acker (2006, p. 448) argues that because women have more obligations outside of work than do men, this gendered organization of work is important in maintaining gender inequality in organizations'.

Despite diversity policies and practices being monitored in the academy, Monroe et al. (2008, p. 215) contend that '[o]vert discrimination has largely given way to less obvious but still deeply entrenched inequities'. The UK academic workforce has been incrementally controlled by government higher education policy metrics (Shattock, 1999; Wilson, 1991). These are often unconducive to women's ways of working and detrimental for women scholars' career progression (Davies et al., 2016; Harley, 2003; Yarrow, 2016) because objectives such as achieving research excellence and impact demand high levels of dedicated and undisturbed time. As women academics typically experience unfair workload allocations (Barrett \& Barrett, 2011) with less time than men for research (Winslow, 2010) which requires significant time 
commitment (Sang et al., 2015), they face disadvantage within gendered cultures, structures and procedures (Benschop \& Brouns, 2003).

The problem is that the lack of awareness or 'invisibility of inequality to those with privilege does not give way easily to entreaties to see what is going on' (Acker, 2006, p. 457). Indeed, Acker (2006, p. 459) argues that '[i]n a culture that ... applauds extreme competitive behavior in pursuit of success, inequality becomes a sign of success for those who win', intensifying gender inequality.

\subsection{Extending Acker's inequality regimes metaphor}

Over 20 years after Acker (1998, p. 200) lamented '[t]he non-responsibility of organizations for human survival and reproduction' that creates workplace disadvantage for women with caring responsibilities in particular, our findings demonstrate the continuing relevance of the notion of gender inequality regimes in the workplace. This paper extends Acker's (2009) focus on women's leadership and the success and failure of organizational initiatives (Acker, 2006) by examining the effects of industry sector policy changes which unintentionally perpetuate gender inequality regimes.

\section{3 | UK RESEARCH IMPACT CASES}

To explore inequality regimes within the context of new policy, we empirically investigate the effects of the introduction of research evaluation for REF impact in the UK's higher education sector. Our insights offer lessons for other national systems as impact evaluation is expanded globally beyond the UK. HEFCE (2016) defined REF impact as 'an effect on, change or benefit to the economy, society, culture, public policy or services, health, the environment or quality of life, beyond academia'. REF policy stipulated that usually one impact case must be submitted for 10 full-time academics whose research outputs were included. This means that 
directors of research rely on assembling a prescribed number of case studies and not every academic is expected to engage with REF impact.

While the chairman and deputy chairwoman of the REF 2014 sub-panel for business and management studies (Pidd \& Broadbent, 2015, p. 571) reported that equality and diversity issues improved in REF 2014 since previous exercises, they mentioned only visible issues such as maternity leave and parental responsibilities. The REF Equality and Diversity Advisory Panel (EDAP) reported on good practice and reviewed universities' codes of practice on staff selection for the REF, recommending ' $[\mathrm{w}]$ ork is still needed to improve...gender equality within academia' (HEFCE, 2015, p. 11). EDAP advises both the HEFCE REF group as well as individual REF panels on measures that promote and cultivate equality and diversity in the REF process. It is notable that EDAP is disproportionately female and has not produced a gender impact assessment of REF impact cases.

What does it take to generate a good REF impact case? Penfield et al. (2014) suggest that well-endowed universities provide the best consultancy and administrative support to produce REF impact cases. Studies of REF impact have emphasized the importance of being able to sell research impact (Watermeyer \& Hedgecoe, 2016). These articles have not, however, paid attention to gender inequality and the implications for infrastructure support and developing skills to sell the value of impact.

\section{4 | METHODOLOGY}

\section{1 | Epistemology}

In using Acker's (2006) inequality regimes approach to understand the under-representation of women management scholars leading research impact case studies, we adopt a subjective interpretivist philosophical position. We frame gender in the data analysis as socially constructed (Butler, 1990). Social construction refers to society and culture creating gender roles which are prescribed as ideal or appropriate behaviour for a person of 
that specific gender, ascribing what constitutes men's and women's work. From this perspective, gender and gendered knowledge are social products. Moreover, Alvesson and Due Billing (2009, p. 49) argued that what is considered men's and women's work plays a fundamental role in subordinating women.

Gender-stereotyping remains entrenched in society despite the many legal (e.g. the Equality Act 2010 in the UK), cultural, and intellectual challenges that have called it into question (Ridgeway, 2011). According to West and Zimmerman (1987, p. 126), gender is 'an emergent feature of social situations: both as an outcome of and a rationale for various social arrangements, and as a means of legitimating one of the most fundamental divisions of society'. Gender performativity (Butler, 1990) is the 'doing' of gender repeatedly aligned to social norms, reifying and reinforcing gender stereotypes through performances that normalise and maintain essential gender types. We were interested in this research to investigate how in 'performing gender' men shaped REF impact as a signalling device to enhance their political, social and career capital to the disadvantage of their women colleagues.

\section{2 | Data collection}

While our starting point in this project was not Benschop and Brouns' (2003) concern with privileged masculine hegemony in the academy, it quickly became apparent from our desk research on cases submitted that women impact case leaders were considerably underrepresented. Quantitative data collection included a count of women leaders of the 410 REF 2014 impact cases for business and management studies that are publicly available. This is a rich data source for reviewing knowledge production in business schools (Hughes et al., 2019).

As in the study by Monroe et al. (2008) of gender inequality in academia, qualitative data in our research consisted of in-depth semi-structured narrative interviews. The interviews lasted 20-40 minutes each and were conducted during December 2017-March 2018 by the second author with a purposive sample of 12 women. The interviewees were at different career 
stages ranging from doctoral student to professor and located in diverse types of business school when the case was submitted. They had been involved in REF 2014 impact cases and were known to the researchers. Interview questions (Appendix 1) were mapped to Acker's (2006, 2009) inequalities regime framework.

\section{3 | Data analysis}

First, we analysed secondary data in the REF 2014 four-page impact cases from www.impact.ref.ac.uk. The whole dataset of 410 cases for business and management studies was the largest unit submitted. The individual academic who led the impact case can be inferred from the narrative and publications. Often this person is one of the most frequently cited authors of the academic articles and practitioner reports provided and named as principal investigator on grants. In some instances, there were multiple successive case leaders. We recorded the leader as the one apparent at the time of submission except where there were successive leaders that included a woman. In these cases both leaders were noted.

Where only surnames were provided, we searched for the person's full name and gender on the internet. Where the lead case author was unclear in one case, we asked the woman professor who led the project for confirmation. Surprisingly, her response was that case leadership was never discussed and so we excluded her case from our study. We categorised 15 cases as 'leader's gender unknown' for cases where individuals did not reply to our email, had moved overseas, and or left academia and we were unable to determine who was the impact case leader. This meant that 395 impact cases were analysed in our final sample. We identified the main REF impact case author as the lead academic at the time of submission as well as any leader involved earlier in generating the case, including co-leaders.

We independently clustered the impact cases into seven categories and then cross-checked anomalies (see Table 1). The categories listed in Table 1 include: sole woman impact author; men and women co-leads; a woman leading a mixed gender team; all women teams. These 
descriptions alerted us to the disproportionately high numbers of cases with no woman team leader, the dominance of men leading mixed gender teams, and the significant number of sole woman or women only authored impact cases. These findings informed the interview questions in our qualitative research design.

To analyse the 12 semi-structured interview transcripts, we used the three-stage Gioia method (Gioia et al., 2013). First order comments from respondents were displayed in a table. These were then open coded under themes and finally emergent patterns of aggregate dimensions were clustered thematically (see Figure 1). From the data, three facets in Acker's (2006, 2009) model emerged as key. These were later developed in Figure 2 to include the influences of policy, societal and sector norms, and individuals that 'gender' the impact case agenda.

Inevitably, there is a risk of the two gender studies scholars in the research team reading into the data analysis gendered inequalities that might not have been apparent to the third researcher in the team whose primary research interest is the management education field. As UK business school colleagues, the respondents understood and encouraged our research aims (Bryman \& Lilley, 2009).

We are insider researchers (Brannick \& Coghlan, 2007) but the two women authors who collected the data were not in academic roles for REF 2014. None of the authors of this article submitted a REF 2014 impact case although the first woman author is leading a REF 2021 case.

In terms of methodological and epistemic reflexivity (Johnson \& Duberley, 2000) about the researcher-research respondent relationship, we were conscious of our own potential impact on the study. The interview recordings and transcripts were discussed within the research team to check for bias. While Brannick and Coghlan (2007, p. 60) maintain that 'insider researchers are native to the setting and so have insights from the lived experience', they are also 'prone to charges of being too close'. We are aware, like Bryman and Lilley (2009, p. 343) who also 
researched their peers, that 'reflexivity about one's own organization and work is limited by familiarity, making it difficult to render the kind of penetrating insight that might be gleaned from a less familiar context.' We did not, however, research our own business schools in-depth (Tietze, 2012) for this study.

In addition, we were mindful of ethical considerations with a woman interviewing women (in this case an early career researcher interviewing women professors). At the same time, this allowed for the interviewer to build rapport and solidarity with women interviewees (Oakley, 2016). It created trust to gain candid insights (Fineman, 2001) and shared understanding within the same profession.

Limitations of our research methodology include desk analysis of impact cases, interviews with only a dozen women impact case writers from England and Scotland and no discussions with men, potential issues of attribution bias (Martinko, 1995), inaccurate recollection (Huber \& Power, 1985), and retrospective sense making (Golden, 1992) when reflecting on impact cases that had been submitted five years previously.

\section{5 | FINDINGS}

The following section presents findings from secondary data that illustrate the underrepresentation of women leading REF 2014 business and management studies impact cases and the gender composition of case teams. We find three facets of Acker's (2006) inequality regime relevant to our coded interview primary data that are clustered from seven emergent themes (Figure 1). One important finding for further investigation were instances when women's impact work was attributed to men, consistent with Acker's (2006) observation. Finally, Figure 2 provides a conceptual framework to capture gendering influences on REF impact case leadership.

\section{1 | Gender composition of REF impact case teams}


Table 1 shows that only $25 \%$ of identifiable REF 2014 business and management case team (co-)leaders in our data were women. Of these impact cases led by women, over half $(54 \%)$ were sole authored. The latter suggests an impoverished model without a team of academics supporting research impact efforts. The second most common configuration in the sample where a woman led a case was joint or successive leadership with a man (20\%). A woman leading a mixed gender team (16\%) was the third most common arrangement in the sample. The least common formation was a team that comprised all women $(10 \%)$. As our focus is on the representation of women, this study did not examine cases led by one man alone or teams that comprised men only.

-----Insert Table 1 here-----

One view expressed by our respondents was that men are naturally dominant in the impact agenda because men are more dominant numerically in business schools. In fact, women represent almost half of UK business school faculty (Metz et al., 2016).

\section{$\mathbf{5 . 2} \mid$ Sector cultural context and norms}

First, in discussing our findings we note a male dominated culture and socially constructed gendered norms in the business school sector where there are distinct disciplinary prejudices. Despite assumptions of meritocracy and fairness in knowledge intensive organizations like universities, cultural norms set by men were apparent in our respondents' experiences. There is gender bias in the research that men and women conduct (Knights \& Kerfoot, 2004) and the value ascribed to certain fields. Steinpórsdóttir et al. (2019) argued that structural gender bias within new managerialism and marketised higher education makes academic women based in feminised fields more vulnerable. It appears to be a norm for men in the academy to appropriate impact to display political capital. We found evidence of men (but not women) gaining kudos from publishing impact cases that peers in patriarchal support systems (Bagilhole \& Goode, 2001) recognised and rewarded. 


\section{$\mathbf{5 . 3}$ | Internal institutional systems and structures}

Second, our findings emphasize internal institutional systems and structures that underpin the extent and type of gender inequality. These include organizational practices, processes, and controls which resulted in relatively low representation of women leading REF 2014 impact cases.

In our study, we found that women faced structural and operational barriers institutionally that hampered their capacity to engage with the research impact case agenda. For example, respondents discussed lack of time and resources allocated in workload models for women to create research impact as publishing journal articles is a top priority (De Rond \& Miller, 2005). Khazragui and Hudson (2014, p. 60) argue that '[a]cademics and universities should always remember that the basis of their reputation, prosperity, and indeed impact ultimately lies with high-quality academic published work'. REF impact cases are of no value if they are not underpinned by publications in excellent peer-reviewed journals so women must first publish or build a team to publish before they can claim REF impact.

Typically, our interviewees pointed out that workload allocation models (WAMs) in the context of New Public Management (Hull, 2006) do not account for the time dedicated to designing, implementing, writing and selling an impact case study. Yarrow (2016) noted that the application of WAMs may provide additional or new opportunities for individual negotiations, particularly surrounding teaching loads and time for research. However, in some cases the application of a workload model that treats everyone the same might actually contribute to gender inequality as personal circumstances are not taken into account. Impact case studies are seen as an additional burden on an already onerous workload. This might explain why some respondents found it acceptable for women to act in support roles while men fronted impact cases because of men's higher status as professors in the business school system. 
The extent and type of gendered inequality in the academy were evident in remarks about preferential rewards for men generating impact cases and women's contributions being ignored. For example, a respondent we interviewed was astonished to observe a younger man being singled out as highly promising for engaging with REF impact at the same time as her own contributions to the REF impact agenda were overlooked. The man's contribution to impact was viewed as highly valuable to the extent that it signalled positive career ambitions for him. Yet the woman's involvement in impact was not taken seriously nor viewed as significant for her career advancement in the academy.

A further distinction between men and women in our findings was made in terms of the type and degree of gender inequality. For instance, women's behind-the-scenes work in writing up impact was viewed by men merely as 'graft'. In contrast, the more exciting and visible aspects of selling impact were attributed to men which raised their profiles in terms of the impact measures of significance and reach. This division of labour with women in support roles and men taking the spotlight appears to compound existing inequalities in the academy where women are disproportionately focused on university teaching and pastoral care and men gain promotions for research and enterprise activities. This was further explained in terms of men's external visibility and focus on income generation, with women academics disadvantaged in interpersonal networking in university-industry projects as a result of gendered practices (Berger et al., 2015). These observations suggest gendered ways in which knowledge is produced, translated, and exchanged (Benschop \& Brouns, 2003). They confirm that still '[a]cademic [knowledge] production is shrouded in masculine norms and values' (Knights \& Richards, 2003, p. 214).

Our findings were consistent with the third dimension in Acker's $(2006,2009)$ framework of systemic 'structural, cultural and procedural' (Benschop \& Brouns, 2003, p. 206) practices, processes, and controls that reinforce inequality in the context of research impact. Knights and 
Richards (2003, p. 213) commented over 15 years ago that the RAE, a precursor to the REF, institutionalised 'masculine norms and practices' and 'meritocratic systems of inequality ... that present disadvantages to a majority of women and some men.' There appears to have been little progress in the meantime, with REF impact case policy reinforcing gendered norms.

\section{4 | Individual position}

In this section, we discuss evidence from our analysis of the interviews about individuals' positioning and (un)equal opportunities based on gender within the impact agenda. Savigny (2019) found that impact involves public media engagement which may negatively affect women as a result of on-line abuse, resulting in the cumulative marginalisation and silencing of women. While we did not find evidence of gender violence such as trolling, our respondents repeatedly mentioned women not being able to engage with the impact agenda at all because of workplace structures, cultures of discrimination and overload. Our interviewees provided examples of cultural sexism in the academy (Savigny, 2014, 2017) with accounts of some men appropriating impact generated by women as their own.

In our study, several individual women discussed time famine, with insufficient time or resources to engage in generating impact cases. Some women researchers simply cannot accommodate another performance metric in the form of research impact over and above the requirement to publish in top academic journals. Women scholars tend to be exhausted by pastoral and teaching activities in universities (Angervall, 2018) and more likely than men to represent the encumbered worker who lacks dedicated time to produce research impact.

It is telling that all four Cambridge University REF 2014 impact cases for business and management included a man's surname in the titles. In contrast to this explicit naming of men leading cases, some women we interviewed who were involved in the REF impact case agenda showed unassertive, non-competitive behaviours about claiming impact case leadership. One 
woman in a support role was pleased to be mentioned in a case at all after she moved to a different university.

The norm of men being submitted as leaders of cases generated by women was explained by men as legitimate because the women had left the institution before the formal REF submission date. Officially, impact cases belong to the institution where they are created and do not move with the academic and so if women are less mobile in their careers this rule may be to their advantage. Other explanations for men claiming women's work in some institutions were that women had completed the groundwork and writing behind the scenes but were not professors and so not entitled to front a case officially. One woman professor said she had genuinely not considered who was leading the case. Another accepted co-leadership as the norm. A third woman respondent had nominated a man who was a doctoral student as lead case author and impact generator.

Although we do not wish to blame women for systemic gender discrimination, it would seem from some of these responses that individual women's practices and actions in relation to selling their own contributions in the impact agenda are less forceful than those of men. At times, women scholars appear to lack the self-promotion and bravado of men in the same position. Such examples point to 'women-centred explanations for gender disparities' (Bird, 2011, p. 202) rather than systemic influences and suggest stereotypes of 'women's lack of selfconfidence' (Powell et al., 2018, p. 139). Ostensibly, women scholars' lack of self-promotion and women professional support staff drafting impact cases for men 'with big titles and big roles' perpetuate Matthew (Merton, 1973) and Matilda effects (Rossiter, 1993) in the impact policy agenda.

Women mentioned men jostling to submit an impact case study and gaining social capital for leading a case. In contrast, women interviewees in the sample presented themselves as collaborative and accommodating. Arguably, men are more proactive in engaging with, 
claiming, communicating, and benefiting from research impact. Several respondents even suggested it was an inevitable and normal state of affairs for men to lead most of the REF 2014 impact because of men's competitive drive and professorial gender imbalance. Authors (all men) of books on research impact such as Alstete et al. (2018) and Reed (2018) appear oblivious to any discussions about gender or gender inequalities within the impact case agenda.

Interesting examples in our interviews with women were those who appeared unaware of gender and leadership issues such as respondents who stated that there was no need to identify the impact case leader or who accepted a professor benefiting from the 'Matthew effect' (Merton, 1973) of gaining recognition for a case that he did not write. One woman claimed that there was always equality in projects she worked on. This raises the question of women accepting co-leadership rather than being the sole leader which may alienate their colleagues but raise the woman's profile. The data in most of the case narratives in our desk research did point to a clear leader. Mainly our respondents supported this view although there was no explicit requirement to indicate a leader in the formal REF impact case submission.

\subsection{Conceptual framework}

To make sense of our data analysis, we used Acker's $(2006,2009)$ inequality regimes framework. We identified six multi-layer and accumulative influences that 'gender' the production of REF impact cases. Figure 2 indicates that socially constructed norms within society more broadly influence the division of labour in the workplace. It appears that new national policy for the UK's higher education sector is shaped by existing gendered workplace norms. In the case of universities, academic disciplinary differences also entrench gender inequalities.

-----Insert Figure 2 here----- 
Our framework shows that inequalities are evident in workplace regimes based on gender, with accepted systems embedding the extent and form of gender discrimination. At the individual level, accumulation of multiple sources of disadvantage for women scholars is explained by time famine, under-recognition (Rossiter, 1993), lack of rewards, and the belittling of gender studies (Knights \& Kerfoot, 2004) which result in women's repeated underrepresentation. Impact cases dominated by men mean that there is likely to be a gender bias in the type of knowledge and impact generated for society. Men become major beneficiaries of REF impact for their career enhancement which enhances their ability to demonstrate impact when applying for research funding to the further disadvantage of women scholars.

Figure 2 demonstrates the cumulative, multi-layered (Layder, 1993) and on-going gendered aspects of the impact agenda in UK universities. Furthermore, Figure 2 indicates the 'functional relationships between variables' (Johns, 2006, p. 386) such as the gendered individual, the societal and policy context of impact case studies, and institutional gender inequality regimes.

When applied to our empirical data, Figure 2 allows us to show that despite assumptions of meritocracy and fairness in a knowledge intensive sector like the business and management education field, consistent with the literature on academic productivity (e.g. Bentley, 2011; Cole \& Singer, 1991; Eisend \& Schuchert-Güler, 2015; Schuchan Bird, 2011), cultural norms set by men which disadvantage women were apparent in the experiences of our respondents. There is gender bias in the research that men and women conduct (Knights \& Kerfoot, 2004) and academic women based in feminised fields are more vulnerable (Steinpórsdóttir et al., 2019) to being discriminated against.

\section{$\mathbf{5 . 6}$ | Summary}

In sum, while Benschop and Brouns (2003, p. 209) believed the Agora model of focusing on the societal benefits of research would mean 'public accountability creates opportunities for 
women', our findings indicate that women management scholars have missed out on opportunities to lead REF 2014 impact case studies that promote engaged scholarship. We found evidence of 'how systemic barriers operate and why these barriers disproportionately disadvantage women' (Bird, 2011, p. 202).

Our findings appear to support Savigny's (2019, p. 14) view that 'wider social and political power structures may be reinforced, rather than challenged...in the Impact agenda [through] ... the silencing of a diversity of women's knowledge'. We argue that inequality regimes are gendering the impact of business schools as the majority of leaders of REF 2014 impact case studies were men and many cases written by women were sole authored, or at worst credited to men instead.

There is an apparent lack of reflexivity in the higher education system and limited awareness of the disproportionately gendered implications of the research impact agenda in terms of everyday equality related to practices, workloads, time management, resources, recognition and rewards. No other study has highlighted the curious absence of women management scholars from REF impact case leadership. This suggests acceptance of the status quo. Our findings demonstrate that institutional regimes allow the gendered (mis)appropriation of the relatively new REF impact evaluation policy.

\section{6 | CONCLUDING REMARKS}

In conclusion, our data in this first study designed to understand why and how women management scholars were under-represented as impact case leaders for REF 2014 show suboptimal talent management arising from 'gendered power' (Broadbridge \& Simpson, 2011, p. 470) in the academy. We suggest that the solution to mitigating the gendering of policy is systemic, i.e. 'it is universities themselves that need fixing, not the women' (Burkinshaw \& White, 2017, p. 1). Yet there remains a knowing-doing gap in universities as Pells (2019) 
observes: '[i]t seems clear that too many institutions are still at a loss as to how to go about rectifying the centuries-old culture of employment that favours men.'

Nevertheless, in researching the effects of new sector-specific policy, we have created 'a space for researching gender at work and the gendering of ... academe' with 'the aim of changing the lives of those who continue to be marginalized' (Lewis \& Pullen, 2018, p. 109). There is a moral case to be made to raise awareness of women's under-representation in leading REF impact cases by 'removing insidious obstacles to women's advancement in academia' (Metz et al., 2016, p. 721). In doing so, we do not seek 'to deny masculine discourses but simply to disrupt their discursive and hierarchical dominance in organizations as a way of restraining their repressive consequences' (Knights \& Kerfoot, 2004, p. 440) for women scholars who must work amidst men's cumulative advantage (DiPrete \& Eirich, 2006). We have a personal responsibility to highlight 'engendering' processes in the academy (Lewis \& Pullen, 2018), particularly when men (mis)appropriate the impact agenda and are unfairly credited with impact in a context of men's dominant values and norms.

This paper sought to illustrate why 'hidden, gendered practices and processes concealed within norms, customs and values' (Broadbridge \& Simpson, 2011, p. 470) have resulted in the under-representation of women management impact case leaders. Structurally, vertical gendered segregation means that women are overburdened with relatively less time than men for research let alone research impact. We have also highlighted the value of men's networking routines (Uhly et al., 2017) to dominate decision-making processes in the academy to the detriment of women.

In the extreme, women are not credited with being a case study leader or joint leader, but act as 'handmaidens' to men whose careers are advanced because of their claims in generating impact cases. This results in suboptimal talent management and leads inevitably to a bias towards men in the way policy reforms are implemented and research impact is designed. It means that policy-makers who are men have not only shaped REF (e.g. Stern, 2016), but have 
mainly determined how REF impact has evolved in practice and what constitutes impactful research in society.

Overall, this article has illustrated not only 'gendering organizations' (Knights \& Rubery, 1994, p. 1) but 'gendering policy'. This is disappointing given that the implementation of national policy on evaluating academic research impact cases was potentially positioned to play to women's strengths 'in an Agora model...[that] entails greater public accountability, social responsibility and transparency' (Benschop \& Brouns, 2003, p. 194). The impact agenda initially offered a structure to help in 'undoing' daily gendered organizational practices in universities (van den Brink \& Benschop, 2012). Unsurprisingly, the cumulative disadvantage for women scholars that was evident in our literature review is mirrored in our empirical data which showed that ' $[\mathrm{t}]$ he gendered lives of organizational members reproduce many of the patterns of the past' (Pullen et al., 2019, p. 2).

To complement our study, further research in this field might explore reasons for women's sole-authored REF impact cases. Interview samples could be expanded to gain insights from more women and to include men who led impact cases and their assistants as well as policymakers. Methodologically, we could draw on dyadic interviews (Morgan et al., 2013), team interviews, and ethnographic methods (e.g. Latour \& Woolgar, 1979) to discuss gender and team dynamics over the life course of an impact case. Cross-disciplinary and international comparative studies would also be insightful as other nations adopt research impact evaluation policies.

Additionally, there is scope to examine the content of impact cases and different configurations of impact case teams (including and beyond business and management studies). Positive exemplars of women who successfully overcame gendered structures (Bird, 2011) can inform our understanding of how women scholars excel despite inequality regimes (Ivancheva et al., 2004). 
Although Knights (2019, p. 27) is optimistic that future generations might regard the 'university's current masculine preoccupations as merely a historical blip', our findings about the imbalance in women leading REF impact cases suggest the opposite. We are hopeful, however, that practical mechanisms can be sustained to support women who work in gender inequality regimes (Acker 2006, 2009). These include peer networks, such as women's peer mentoring and networking fora in universities (O’Meara \& Stromquist, 2015) and amongst management scholars, e.g. CYGNA https://harzing.com/cygna and the EGOS (European Group for Organization Studies) Women's Network. Additional ideas to enhance women's representation are "[i]mpact buddy' arrangements where colleagues agree to respond quickly to others' blogs, media contributions' and other impact related activities (Campbell \& Childs, 2013, p. 188). Dedicated funding, administrative support, incorporating time for impact in workloads, and recognising impact cases in promotions can also facilitate women's engagement with the impact agenda. The creation of new positions such as impact fellows designed to encourage women to lead and engage more with impact cases could be based on a strengths-based approach rather than on the unrealistic expectation of individuals achieving high performance metrics in all aspects of an academic's role.

Finally, while the new impact policy agenda has been effective in showcasing the wider beneficiaries of university research, there is an imperative to inform decision-makers (Steinpórsdóttir et al., 2019) and academics about our findings that only a quarter of REF 2014 business and management cases were led by women. We call for 'academic activism' (Rhodes et al., 2018, p. 139) with the aim of 'unsettling' (Bird, 2011) gendered bureaucracies in higher education through political intervention. In doing so, we welcome impact cases that demonstrate how academics 'embrace the political potential ... to render [their own] organizations accountable and responsible for change' (Pullen et al., 2019, p. 2) that mitigates gender disadvantage for women management scholars. It is vital that barriers which prevent women from leading in the academy (Howe-Walsh \& Turnbull, 2016), ethical issues of the 
misappropriation and under-recognition of women's outputs, and mechanisms for 'disengendering' the workplace are explicitly addressed in the increasingly important research impact policy agenda (Yarrow \& Davies, 2018) that is burgeoning globally.

\section{ACKNOWLEDGEMENTS}

Many thanks to our $G W O$ editor Alison Pullen and two reviewers as well as to colleagues at the 2017 Academy of Management meeting in Atlanta for their constructive and detailed comments on this manuscript. We are also grateful to the interviewees in this study for their valuable insights.

\section{DECLARATION OF CONFLICTING INTEREST}

The authors declared no potential conflicts of interest with respect to the authorship and/or publication of this article.

\section{REFERENCES}

Abramo, G., Cicero, T., \& D'Angelo, C. A. (2011). The dangers of performance-based research funding in non-competitive higher education systems. Scientometrics, 87(3), 641-654. doi: 10.1007/s11192-011-0355-4

Acker, J. (1998). The future of "gender and organisations": Connections and boundaries. Gender, Work and Organization, 5(4), 195-206.

Acker, J. (2006). Inequality regimes: Gender, class, and race in organizations. Gender and Society, 20(4), 441-464. doi: 10.1177/0891243206289499

Acker, J. (2009). From glass ceiling to inequality regimes. Sociologie du Travail, 51(4), 199217. doi: 10.1016/j.soctra.2009.03.004

Adler, N., \& Harzing, A-W. (2009). When knowledge wins: Transcending the sense and nonsense of academic rankings. Academy of Management Learning \& Education, 8(1), 72-95. doi: 10.5465/AMLE.2009.37012181

Aguinis, H., Suarez-Gonzalez, I., Lannelongue, G., \& Joo, H. (2012). Scholarly impact revisited. Academy of Management Perspectives, 26(2), 105-132. doi: 10.5465/amle.2013.0013

Aiston, S. J., \& Jung, J. (2015). Women academics and research productivity: An international comparison. Gender and Education, 27(3), 205-220. https://doi.org/10.1080/09540253.2015.1024617.

Alstete, J. W., Beutell, N. J., \& Meyer, J. P. (2018). Evaluating scholarship and research impact: History, practices and policy development. Bingley, UK: Emerald.

Alvesson, M., \& Billing, Y. D. (2009). Understanding gender and organizations. London, UK: Sage. 
Angervall, P. (2018). The academic career: A study of subjectivity, gender and movement among women university lecturers. Gender and Education, 30(1), 105-118. https://doi.org/10.1080/09540253.2016.1184234

Atewologun, D., \& Sealy, R. (2014). Experiencing privilege at ethnic, gender and senior intersections. Journal of Managerial Psychology, 29(4), 423-439. https://doi.org/10.1108/JMP-02-2013-0038

Bagilhole, B., \& Goode, J. (2001). The contradiction of the myth of individual merit, and the reality of a patriarchal support system in academic careers. European Journal of Women's Studies, 8(2), 161-180.

Barrett, L., \& Barrett, P. (2011). Women and academic workloads: Career slow lane or culde-sac? Higher Education, 61(2), 141-155. doi 10.1007/s10734-010-9329-3

Benschop, Y., \& Brouns, M. (2003). Crumbling ivory towers: Academic organizing and its gender effects. Gender, Work \& Organization, 10(2) 194-212. doi: 10.1111/14680432.t01-1-00011

Bentley, P. (2011). Gender differences and factors affecting publication productivity among Australian university academics. Journal of Sociology, 48(1), 85-103. doi: $10.1177 / 1440783311411958$

Berger, L., Benschop, Y., \& van den Brink, M. (2015). Practising gender when networking: The case of university-industry innovation projects. Gender, Work \& Organization, 22(6), 556-578. doi:10.1111/gwao.12104

Berns, S. (2002) Women going backwards: Law and change in a family unfriendly society. Aldershot, UK: Dartmouth Publishing.

Bird, S. R. (2011). Unsettling universities' incongruous, gendered bureaucratic structures: A case-study approach. Gender, Work \& Organization, 18(2), 202-230. https//doi: 10.1111/j.1468-0432.2009.00510.x

Brannick, T., \& Coghlan, D. (2007). In defense of being "native". The case for insider academic research. Organizational Research Methods, 10(1), 59-74.

Broadbridge, A., \& Simpson, R. (2011). 25 years on: Reflecting on the past and looking to the future in gender and management research. British Journal of Management, 22(3), 470-483. https//doi:10.1111/j.1467-8551.2011.00758.x

Brooks, C., Fenton, E., \& Walker, J. (2014). Gender and the evaluation of research. Research Policy, 43(6), 990-1001. https//doi: 10.1016/j.respol.2013.12.005

Bryman, A., \& Lilley, S. (2009). Leadership researchers on leadership in higher education. Leadership, 5(3), 331-346. doi: 10.1177/1742715009337764

Burkinshaw, P., \& White, K. (2017). Fixing the women or fixing universities: Women in HE leadership. Administrative Sciences, 7(30), 1-14. doi:10.3390/admsci7030030

Butler, J. (1990). Gender trouble: Feminism and the subversion of identity. New York, NY and London, UK: Routledge.

Campbell, R. \& Childs, S. (2013). The impact imperative: Here come the women:-). Political Studies Review, 11(2): 182-189. doi: 10.1111/1478-9302.12008

Cole, J. R., \& Singer B. (1991). A theory of limited differences: Explaining the productivity puzzle in science. In H. Zuckerman, J. R. Cole, \& J. T. Bruer (Eds.), The outer circle: Women in the scientific community (pp. 277-310). New York, NY: W. W. Norton and Co. 
Crane, D. (1972). Invisible colleges: Diffusion of knowledge in scientific communities. Chicago, IL: University of Chicago Press.

Davies, C., Healey, R. L., \& Cliffe, A. D. (2016). Scaling the mountain: An exploration of gendered experience of academic staff in relation to the Research Excellence Framework 2014. https://chesterrep.openrepository.com/handle/10034/600502

De Rond, M., \& Miller, A. N. (2005). Publish or perish: Bane or boon of academic life? Journal of Management Inquiry, 14(4), 321-329. doi: 10.1177/1056492605276850

de Solla Price, D. J., \& Beaver, D. (1966). Collaboration in an invisible college. American Psychologist, 21(11), 1011-1018. https//doi:10.1037/h0024051

DiPrete, T. A., \& Eirich, G. M. (2006). Cumulative advantage as a mechanism for inequality: A review of theoretical and empirical developments. Annual Review of Sociology, 32(1), 271-297. doi: 10.1146/annurev.soc.32.061604.123127

Eisend, M., \& Schuchert-Güler, P. (2015). Journal publication success of German business researchers: Does gender composition and internationality of the author team matter? Business Research, 8(2), 171-188. doi 10.1007/s40685-015-0019-y

Fineman, S. (2001, August). Managing emotions at work: Some political reflections. Academy of Management Symposium, Washington DC.

Fletcher, C. (2007). Passing the buck: Gender and management of research production in UK higher education. Equal Opportunities International, 26(4), 269-286. http://dx.doi.org/10.1108/02610150710749395

Gieryn, T. F. (1983). Boundary-work and the demarcation of science from non-science: Strains and interests in professional ideologies of scientists. American Sociological Review, 48(6), 781-795. https://doi.org/10.2307/2095325

Gioia, D. A., Corley, K. G., \& Hamilton, A. L. (2013). Seeking qualitative rigor in inductive research: Notes on the Gioia methodology. Organizational Research Methods, 16(1), 1531. https://doi-org.libaccess.hud.ac.uk/10.1177/1094428112452151

Golden, B. R. (1992). Research notes. The past is the past - or is it? The use of retrospective accounts as indicators of past strategy. Academy of Management Journal, 35(4), 843860 .

Haley, U. C. V., Page, M. C., Pitsis, T. S., Rivas, J. L., \& Yu, K. F. (2017, November 14). Measuring and achieving scholarly impact. A report from the Academy of Management's practice theme committee. New York, NY: Academy of Management.

Harley, S. (2003). Research selectivity and female academics in UK universities: From gentleman's club and barrack yard to smart macho? Gender and Education, 15(4), 377392. https//doi/abs/10.1080/09540250310001610580

Harris, C., Ravenswood, K., \& Myers, B. (2013). Glass slippers, holy grails and ivory towers: Gender and advancement in academia. Labour \& Industry, 23(3), 231-244. https//doi/full/10.1080/10301763.2013.839084

HEFCE (2015). Equality and diversity in the 2014 Research Excellence Framework. A report by the equality and diversity panel. Bristol, UK: Higher Education Funding Council for England.

HEFCE (2016). REF impact.

http://webarchive.nationalarchives.gov.uk/20180319120009/http://www.hefce.ac.uk/rsr ch/REFimpact/ 
Heijstra, T. M., Steinthorsdóttir, F. S., \& Einarsdóttir, T. (2017). Academic career making and the double-edged role of academic housework. Gender and Education, 29(6), 764780. https://doi.org/10.1080/09540253.2016.1171825

HESA (2015, August 19) Overview of the academic year 2013/14. https://www.hesa.ac.uk/news/19-08-2015/overview-of-the-academic-year

HESA (2019, January 24). Higher education staff statistics: UK, 2017/18. https://www.hesa.ac.uk/news/24-01-2019/sb253-higher-education-staff-statistics

Howe-Walsh, L., \& Turnbull, S. (2016). Barriers to women leaders in academia: Tales from science and technology. Studies in Higher Education,41(3), 415-428. https://doi.org/10.1080/03075079.2014.929102

Huber, G. P., \& Power, D. J. (1985). Retrospective reports of strategic-level managers: Guidelines for increasing their accuracy. Strategic Management Journal, 6(2), 171-180.

Hughes, T., Webber, D., \& O'Regan, N. (2019). Achieving wider impact in business and management: Analysing the case studies from REF 2014. Studies in Higher Education, 44(4), 628-642. https//doi: 10.1080/03075079.2017.1393059

Hull, R. (2006). Workload allocation models and "collegiality" in academic departments. Journal of Organizational Change Management, 19(1), 38-53.

Ivancheva, M., Lynch, K., \& Keating, K. (2004). Precarity, gender and care in the neoliberal academy. Gender, Work \& Organization, 1-15. doi: 10.1111/gwao.12350

Johns, G. (2006). The essential impact of context on organizational behavior. Academy of Management Review, 31(2), 386-408. http://dx.doi.org/10.2307/20159208

Johnson, P., \& Duberley, J. (2000). Understanding management research. London, UK: Sage.

Kellard, N., \& Śliwa, M. (2016, November 24). The organisational contexts in which research with impact is produced: Lessons from REF2014. LSE Impact Blog. http://blogs.lse.ac.uk/impactofsocialsciences/2016/11/24/the-organisational-contexts-inwhich-research-with-impact-is-produced-lessons-from-ref2014/.

Khazragui, H., \& Hudson, J. (2014). Measuring the benefits of university research: Impact and the REF in the UK. Research Evaluation, 24(1), 51-62. doi:10.1093/reseval/rvu028

Knights, D. (2019). Gender still at work: Interrogating identity in discourses and practices of masculinity. Gender, Work \& Organization, 26(1), 18-30. doi: 10.1111/gwao.12338

Knights, D., \& Kerfoot, D. (2004). Between representations and subjectivity: Gender binaries and the politics of organizational transformation. Gender, Work \& Organization, 11, 430-454. https//doi/abs/10.1111/j.1468-0432.2004.00241.x

Knights, D., \& Richards, W. (2003). Sex discrimination in UK academia. Gender, Work \& Organization, 10(2), 213-238. https//doi/abs/10.1111/1468-0432.t01-1-00012

Knights, D., \& Rubery, J. (1994). Editors' introduction. Gender, Work and Organization, 1(1), 1. doi: 10.1111/gwao.12330

Kyvik, S. (1991). Productivity in academia: Scientific publishing at Norwegian universities. Oslo: Norwegian University Press.

Latour, B., \& Woolgar, S. (1979). Laboratory life. The construction of scientific facts. Beverly Hills, CA: Sage.

Layder, D. (1993). New strategies in social research: An introduction and guide. Cambridge, UK: Polity Press. 
Lejeune, C., Davies, J., \& Starkey, K. (2015). The impact of the impact agenda. Global Focus, 9(2), 44-47.

Lewis, L., \& Pullen, A. (2018). Gender, Work and Organization in 2018. Gender, Work \& Organization, 25(2): 107-109. https//doi:10.1111/gwao.12248

Marini, G., \& Meschitti, V. (2018). The trench warfare of gender discrimination: Evidence from academic promotions to full professor in Italy. Scientometrics, 115(2), 989-1006. https://doi.org/10.1007/s11192-018-2696-8

Martinko, M. J. (1995). The nature and function of attribution theory within the organizational sciences. In M. J. Martinko (Ed.) Attribution theory: An organizational perspective (pp. 7-16). Delray Beach, FL: St. Lucie Press.

Maxwell, N., Connolly, L., \& Ní Laoire, C. (2019). Informality, emotion and gendered career paths: The hidden toll of maternity leave on female academics and researchers. Gender, Work and Organization, 26(2), 140-157. https//doi: 10.1111/gwao.12306

Merton, R. K. (1973). The Matthew effect in science. In N. W. Storer (Ed.), The sociology of science (pp. 439-459). Chicago, IL: University of Chicago Press.

Metz, I., \& Harzing, A-W. (2012). Gender diversity in editorial boards: An update. A longitudinal study of management journals. Personnel Review, 41(3) 283-300. https:// doi.org/10.1108/00483481211212940

Metz, I., Harzing, A. W., \& Zyphur, M. J. (2016). Of journal editors and editorial boards: Who are the trailblazers in increasing editorial board gender equality? British Journal of Management, 27(4), 712-726. https//doi: 10.1111/1467-8551.12133

Mingers, J., \& Willmott, H. (2013). Taylorizing business school research: On the 'one best way' performative effects of journal ranking lists. Human Relations, 66(8), 1051-1073. https//doi/abs:10.1177/0018726712467048

Monroe, K., Ozyurt, S., Wrigley, T., \& Alexander, A. (2008). Gender equality in academia: Bad news from the trenches, and some possible solutions. Perspectives on Politics, 6(2), 215-233. https://doi.org/10.1017/S1537592708080572

Morgan, D. L., Ataie, J., Carder, P., \& Hoffman, K. (2013). Introducing dyadic interviews as a method for collecting qualitative data. Qualitative Health Research, 23(9), 12761284. doi: $10.1177 / 1049732313501889$

Neyland, D. (2007). Achieving transparency: The visible, invisible and divisible in academic accountability networks. Organization, 14(4), 499-516. doi: $10.1177 / 1350508407078050$

O’Meara, K., \& Stromquist, N. P. (2015). Faculty peer networks: Role and relevance in advancing agency and gender equity. Gender and Education, 17(3), 338-358. https://doiorg.libaccess.hud.ac.uk/10.1080/09540253.2015.1027668

Oakley, A. (2016). Interviewing women again: Power, time and the gift. Sociology, 50(1), 195-213. doi: 10.1177/0038038515580253

Padavic, I., Ely, R. J., \& Reid, E. M. (2019). Explaining the persistence of gender inequality: The work-family narrative as a social defense against the 24/7 work culture. Administrative Science Quarterly, 1-51. doi: 10.1177/0001839219832310 
Pells, R. (2019, May 7). Experts debate merits of approaches including across-the-board rises for women and the longer, harder challenge of changing cultures. Times Higher Education.

Penfield, T., Baker, M. J., Scoble, R., \& Wykes, M. C. (2014). Assessment, evaluations, and definitions of research impact: A review. Research Evaluation, 23(1), 21-32. doi:10.1093/reseval/rvt021

Pidd, M., \& Broadbent, J. (2015). Business and management studies in the 2014 Research Excellence Framework. British Journal of Management, 26(4), 569-581. https://doi.org/10.1111/1467-8551.12122

Powell, S., Ah-King, M., \& Hussénius, A. (2018). 'Are we to become a gender university?' Facets of resistance to a gender equality project. Gender, Work and Organization, 25(2), 127-143. https://doi.org/10.1111/gwao.12204

Probert, B. (2005). 'I just couldn't fit it in': Gender and unequal outcomes in academic careers. Gender, Work and Organization, 12(1), 50-72. https//doi: abs/10.1111/j.14680432.2005.00262.x

Pullen, A., Lewis, P., \& Ozkazanc-Pan, B. (2019). A critical moment: 25 years of Gender, Work and Organization. Gender, Work and Organization, 26(1), 1-8. https//doi: 10.1111/gwao.12335

Reed, M. S. (2018). The research impact handbook. $2^{\text {nd }}$ edition. Huntly: Fast Track Impact.

Rhodes, C., Wright, C., \& Pullen, A. (2018). Changing the world? The politics of activism and impact in the neoliberal university. Organization, 25(1), 139-147. https//doi: $10.1177 / 1350508417726546$

Ridgeway, C. (2011). Framed by gender: How gender inequality persists in the modern world. New York, NY: Oxford University Press.

Rossiter, M. W. (1993). The Matthew Matilda effect in science. Social Studies of Science, 23(2), 325-341.

Sang, K., Powell, A., Finkel, R., \& Richards, J. (2015). 'Being an academic is not a 9-5 job': Long working hours and the 'ideal worker' in UK academia. Labour \& Industry: A Journal of the Social and Economic Relations of Work, 25(3), 235-249. https//doi: 10.1080/10301763.2015.1081723

Savigny, H. (2014). Women, know your limits: Cultural sexism in academia. Gender and Education, 26(7), 794-809. https//doi/abs/10.1080/09540253.2014.970977

Savigny, H. (2017). Cultural sexism is ordinary: Writing and re-writing women in academia. Gender, Work and Organization, 24(6), 643-655. https//doi:10.1111/gwao.12190

Savigny, H. (2019). The violence of impact: Unpacking relations between gender, media and politics. Political Studies Review, https://doi.org/10.1177/1478929918819212

Shattock, M. (1999). Governance and management in universities: The way we live now. Journal of Education Policy, 14(3), 271-282. https//doi: 10.1080/026809399286341

Śliwa, M., \& Johansson, M. (2014). The discourse of meritocracy contested/reproduced: Foreign women academics in UK business schools. Organization, 21(6), 821-843. https//doi.org/10.1177/1350508413486850 
Steinpórsdóttir, F. S., Brorsen Smidt, T., Pétursdóttir, G. M., Einarsdóttir, P., \& Le Feuvre, N. (2019). New managerialism in the academy: Gender bias and precarity. Gender, Work and Organization, 26(2), 124-139. https//doi.org/10.1111/gwao.12286.

Stern, N. (2016). Building on success and learning from experience: An independent review of the Research Excellence Framework. London, UK: Department for Business, Energy and Industrial Strategy.

Tietze, S. (2012). Researching your own organization. In G. Symon \& C. Cassell (Eds.), Qualitative organizational research. Core methods and current challenges (pp. 53-71). Los Angeles, CA: Sage.

Tower, L. E., \& Latimer, M. (2016). Cumulative disadvantage: Effects of early career childcare issues on faculty research travel. Affilia, 31(3), 317-330. https//doi.org/10.1177/0886109915622527

Uhly, K. M., Visser, L. M., \& Zippel, K. S. (2017). Gendered patterns in international research collaborations in academia. Studies in Higher Education, 42(4), 760-782.

van den Brink, M., \& Benschop, Y. (2012). Slaying the seven-headed dragon: The quest for gender change in academia. Gender, Work and Organization, 19(1), 71-92. https//doi: 10.1111/j.1468-0432.2011.00566.x

Watermeyer, R., \& Hedgecoe, A. (2016). Selling 'impact': Peer reviewer projections of what is needed and what counts in REF impact case studies. A retrospective analysis. Journal of Education Policy, 31(5), 651-665. https://doi.org/10.1080/02680939.2016.1170885

West, C., \& Zimmerman, D. H. (1987). Doing gender. Gender \& Society, 1(2), 125-151.

Willmott, H. (1995). Managing the academics: Commodification and control in the development of university education in the UK. Human Relations, 48(9), 993-1027. https//doi:10.1177/001872679504800902

Wilson, T. (1991). The proletarianisation of academic labour. Industrial Relations Journal, 22(4), 250-262. https//doi.org/10.1111/j.1468-2338.1991.tb00642.x

Winslow, S. (2010). Gender inequality and time allocations among academic faculty. Gender and Society. 24(6), 769-793. https//doi:10.1177/0891243210386728

Yarrow, E. (2016). National research evaluation and its effects on female academics, careers in the UK: A case study. Unpublished PhD thesis, London, UK: Queen Mary, University of London.

Yarrow, E., \& Davies, J. (2018, March 8). The gendered impact agenda - how might more female academics' research be submitted as REF impact case studies? LSE Impact Blog. Retrieved from https://blogs.lse.ac.uk/impactofsocialsciences/2018/03/08/the-genderedimpact-agenda-how-might-more-female-academics-research-be-submitted-as-refimpact-case-studies/

\section{APPENDIX 1. Semi-structured interview questions}

1. To what extent do you see women scholars engaging with the impact case agenda? 
2. What was the gender, age and seniority composition of the team (if more than one member) who worked on the impact case you were involved in?

3. Do you think that women management scholars were fairly represented in the composition of the team?

4. Was the impact based on gender issues with publications in journals on gender?

5. Describe the behaviours of those who mainly generated the impact over time, the underpinning research, and who claimed the impact.

6. Did you initiate your involvement in the case or were you invited?

7. What was your role, division of labour, and your experiences of this case? E.g. engagement with beneficiaries of the impact, writing the case, showcasing the impact.

8. What frustrations did you experience during your involvement with the case?

9. Are you in a position where you can dedicate most of your time to your job?

10. What kind of time commitment and opportunity cost did the case entail for you?

11. Do you consider that there was fair recognition of individuals' contributions in terms of workloads and the time constraints for individual members of the team with caring responsibilities? Do you think that some team members took more credit than was due?

12. What kind of institutional structures and processes were in place to support the production of the case and your involvement?

13. How do you think involvement in the case has helped the career advancement of yourself and the other team members? Do you detect any differences for men and women?

14. Did you see any examples of gender inequality in the culture and processes involved in producing the impact case or in other cases? If so, how would you describe the type and extent of this?

15. Are you on any influential journal rankings, editorial, appointment and other panels?

16. Do you consider that universities, and business schools in particular, are gendered institutions?

17. Do you see any differences in the behaviours of men and women academics in relation to REF impact policy?

18. Are you surprised with our findings that only a quarter of REF 2014 impact cases in business and management studies were led by a woman and over half of these were sole authored? 
19. What do you think are the implications for this under-representation of women in terms of the type of impact generated for society?

20. Why do you think women scholars do (or do not) engage with the impact case agenda?

21. What suggestions do you have to support greater representation of women in the impact agenda?

22. Is there anything further you would like to add about the level of women's representation in leading REF impact cases in business and management studies to demonstrate the reach and significance of their research impact and any lessons learned?

Table 1: Women (co)leading REF 2014 business and management studies impact cases

\section{REF 2014 Impact Case Team Configurations for Business and Management Studies \\ Women Leaders (in 394 of 410 cases where gender was identified)}

(1) Sole woman

$13.7 \%$

(2) Women and men co-leaders

(concurrent or successive)

$5 \%$

(3) Woman lead, mixed gender team

$4 \%$

(4) Woman lead, all women team

$2.5 \%$

Total

$25.2 \%$ 


\section{$1^{\text {st }}$ Order \\ Concepts}

- There's also this intangibility as to what makes good impact. And it varies so much, you know, by discipline and by case. Work on gender isn't taken seriously.

- The kind of research that most of the women I work with do has an external impact. What is valued, though, is very masculine, and certainly in business schools, very geared to making money.

- Well, it involved a lot of time that wasn't recognised whatsoever on the workload model, so you just had to do it. You weren't given any time or resources to do it. You just had to do it on top of whatever else you were doing. And it was very time consuming. It kind of went through lots of different iterations. I remember complaining I could have written a whole other paper in the time.

- Business schools don't rate equality. You know, equality doesn't make money. It doesn't make profit. It costs money, you know, and so it's just not very highly rated in business schools, which are very male dominated especially amongst the professoriate.

- I think more women would have done it if they'd had more time.

- If you've got to publish academic journal articles and do all that's actually allocated on your workload, then there just isn't time for anything else like impact cases.

- Actually it was quite interesting, I did notice a change in attitude towards my junior colleague. His impact case study really seemed to work wonders for him in terms of his position in the department. Whereas, you know, I got absolutely no benefit. My impact case wasn't recognised as making an important contribution.

- I [female] was grateful the director of research [male] included my work in his case.

- I think in business studies, and certainly in business studies here, there was a woman or women, who wrote a lot and got through a lot in the background. So I think we need to distinguish between who is doing the grafting and making the impact, and who is seen as the case leader which is often a senior man, a professor.

- Well, it was the work of my doctoral student [male]. So we put him as the lead person. I [female] have since happily retired. - I [female] was involved in two impact cases with a male colleague. His name was down as the lead on the business case. Mine went on the other case that was submitted to another unit of assessment.

- It was my impact but after I [female] left for a promotion, the case was assigned to my boss [male professor].

- You know, we never discussed who the lead was. We were all in the project together, it just wasn't an issue.

- It's always equal, all co-authorship, I [female] don't claim to be the leader.

\section{2nd Order \\ Themes \\ Aggregate \\ Dimensions}

1. Socially

constructed gendered norms

2. Gendering of CULTURAL CONTEXT \& national policy NORMS

3. Discrimination

based on

allocation of

resources

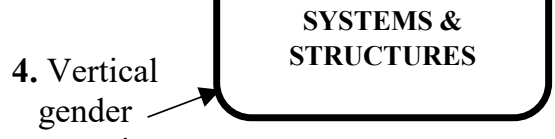
segregation

5. Ideal

unencumbered

worker

6. Personal recognition, visibility

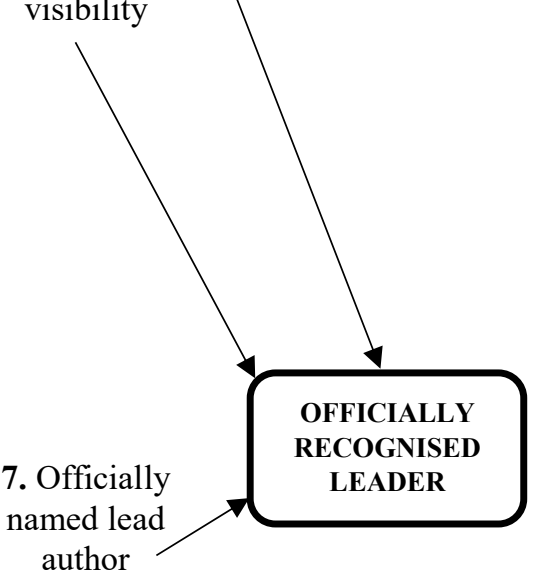




\section{(1) SOCIETAL CONTEXT}

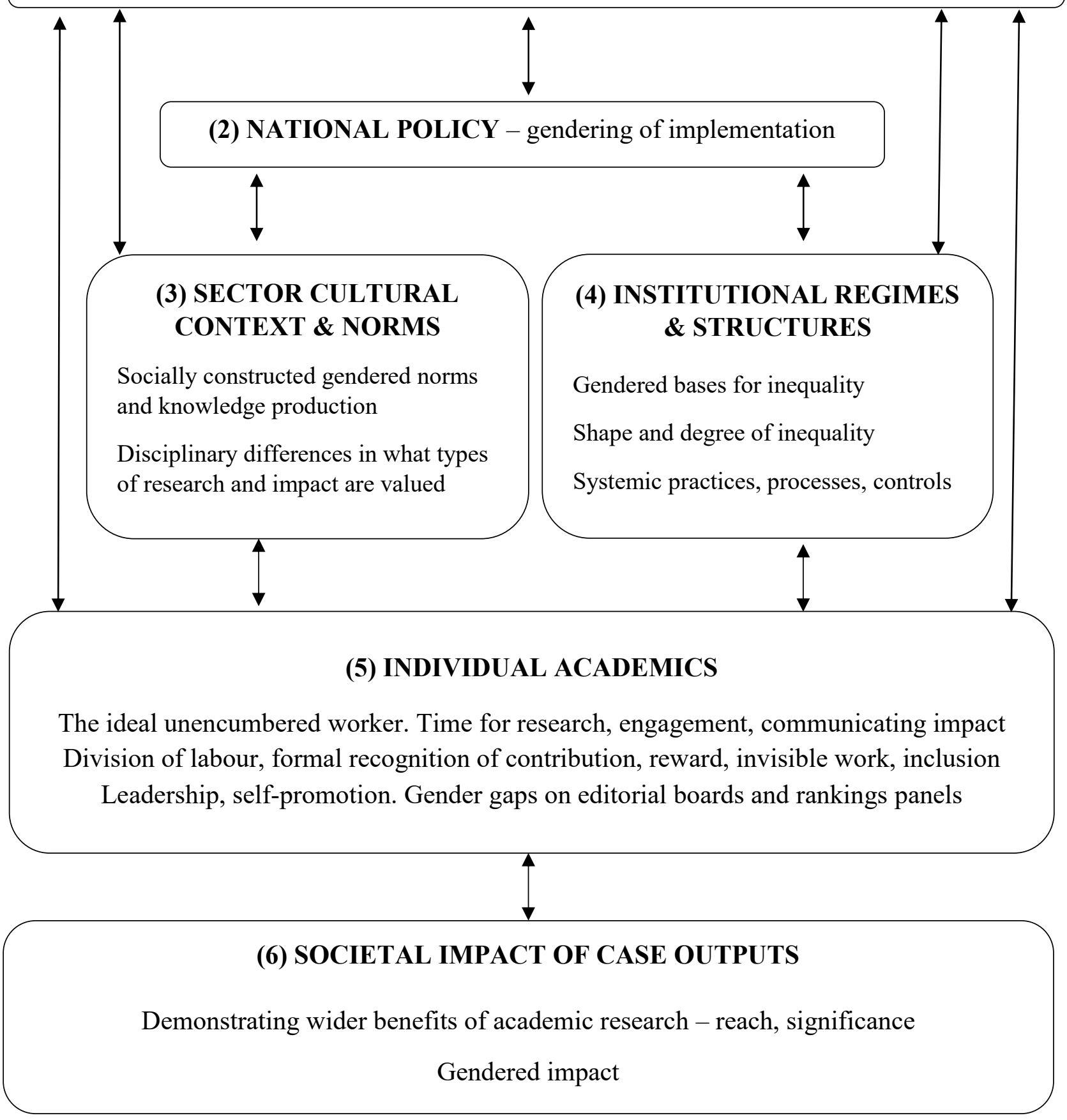

Figure 2: Conceptual framework: Gendering influences on impact case leadership

\section{AUTHOR BIOGRAPHIES}

Julie Davies is a Reader at Manchester Metropolitan University. Formerly she was a Subject Group Leader Research \& Enterprise at Huddersfield Business School. Her research interests 
include HRM in regional SMEs such as ethnic minority micro-enterprises, hospices and emergency hospital services; the international business school field, and the role of membership associations and career boundaries. Julie completed her $\mathrm{PhD}$ in strategic management at Warwick University and she is a practitioner Fellow of the Chartered Institute of Personnel and Development.

Emily Yarrow is a Lecturer at Portsmouth Business School Previously she was a Teaching Fellow and Researcher at the University of Edinburgh Business School. Emily's research interests include HRM, equality and diversity, organisational behaviour/theory, and crosscultural management. Her research focuses on the impact of research evaluation on female academics' careers, pensions, and the experiences of older workers. Emily has recently worked on Scottish Government projects and corporate consultancy. She completed her $\mathrm{PhD}$ at Queen Mary University London.

Jawad Syed is Professor of Organisational Behaviour at Lahore University of Management Sciences where he is Dean of Suleman Dawood School of Business. His research interests include international human resource management, diversity management, business ethics and organisational knowledge. Previously, he worked at the University of Huddersfield (2014-16) and University of Kent (2007-14). Jawad obtained his $\mathrm{PhD}$ in business from Macquarie University and he is an Academic Fellow of the Chartered Institute of Personnel and Development. 